\title{
Benzimidazole Fungicides in Environmental Samples: Extraction and Determination Procedures
}

\author{
$\mathrm{M}^{\mathrm{a}}$ Esther Torres-Padrón ${ }^{1}$, Jana Aufartová2, \\ Zoraida Sosa-Ferrera ${ }^{1}$ and José Juan Santana-Rodríguez ${ }^{1}$ \\ ${ }^{1}$ Department of Chemistry. Faculty of Marine Sciences. University of Las Palmas de Gran \\ Canaria. 35017. Las Palmas de Gran Canaria, \\ 2Department of Analytical Chemistry, Faculty of Pharmacy, Charles University, \\ 50005Hradec Králové, \\ ${ }^{1}$ Spain \\ ${ }^{2}$ Czech Republic
}

\section{Introduction}

Because of the widespread use of agricultural pesticides for different applications, the pesticide residues may present a main source of pollution, which poses risks to plant, animal and human health. Benzimidazole fungicides (BFs) are the largest chemical family that have an imidazole ring containing both acidic and basic nitrogen atoms. They are used for prevention and treatment of parasitic infections in agriculture and aquaculture and are efficient at low doses as well as they inhibit the development of a wide variety of fungi. Some benzimidazoles have also found applications as pre- or post-harvest fungicides for control of a wide range of pathogens. They are either applied directly to the soil, or sprayed over crop fields (Wu et al., 2009). Most of these compounds persist in the environment after their application, with some even remaining for many years. This group includes thiabendazole analogues and benzimidazole carbamates.

Thiabendazole (TBZ) was the first benzimidazole to be marketed. After its introduction, a number of alternative benzimidazoles offering similar activity came on the market, such as parbendazole (PAR), cambendazole (CAM), mebendazole (MBZ), fuberidazole (FDZ) and oxibendazole (OXI). BFs possessing sulphide and sulphoxide functional groups were subsequently introduced, offering a wider spectrum of activity and efficacy. Albendazole (ABZ), fenbendazole (FBZ), triclabendazole (TCB) and oxfendazole (OFZ) have been used in the treatment of different stages of gastrointestinal nematodes. Luxabendazole (LUX) is another benzimidazole-sulphide used but is not licensed for use in the European Union. Netobimin (NETO) and febantel (FEB), which are the pro-drugs of ABZ and FBZ, respectively, have greater water solubility resulting in improved absorption and increased bioavailability. Similar probenzimidazoles have found widespread use as fungicidal agents, including benomyl (BNM) and thiophanate-methyl (TPM), which are precursors of carbendazim (MBC). Such modifications have given rise to new BFs with much slower rates of elimination, higher potencies and broader activity spectra.It is well established that $\mathrm{MBC}$, the common stable 
metabolite of BNM and TPM, is considered as the major fungitoxic principle of the benzimidazole precursor fungicides. Accordingly, regulatory limits for these fungicides are generally all expressed as $\mathrm{MBC}$, the single measurement marker for the food safety or environmental impact of the total benzimidazole-containing residues (Danaher et al., 2007).

The octanol-water partition coefficient, $\mathrm{K}_{\mathrm{ow}}$, is an important property because it can provide an indication of the solubility of these residues in different solvents and give an indication of the elution conditions necessary for liquid chromatography. Most of these molecules have similar $\mathrm{K}_{\mathrm{ow}}$ values, which are generally in the range 0.8-3.3. Under suitable conditions, molecules may be protonated $\left(\mathrm{pK}_{\mathrm{a}} \sim 5-6\right)$ or deprotonated $\left(\mathrm{pK}_{\mathrm{a}} \sim 12\right)$. Few $\mathrm{pK}_{\mathrm{a}}$ values have been published but a summary of the experimental $\mathrm{pK}_{\mathrm{a}}$ values and calculated octanol-water partition coefficients $\left(\mathrm{K}_{\mathrm{ow}}\right)$ are listed in Table 1 .

Although many public benefits have been realized by the use of benzimidazole compounds, their potential impact in both the environment and public health cannot be disregarded. Even if acute toxic effects of benzimidazole compounds are scarce due to their high lethal dose 50 values, several toxic effects have been associated to a chronic exposure to benzimidazole compounds, such as teratogenicity, congenic malformations, polyploidy, diarrhea, anemia, pulmonary edemas, or necrotic lymphoadenopathy.

On account of their extensive use, residual environmental impact and toxic effects at low levels, regulations have set maximum residue levels (MRLs) for benzimidazoles and their metabolites to ensure consumer safety with the range of $0.01-10 \mathrm{mg} \mathrm{kg}^{-1}$, depending on the fungicide-commodity combination (Plant Protection-Pesticide Residues-Regulation (EC) No. 396, 2005). In particular, for most benzimidazoles, the marker residue tolerance has recently been defined as the sum of a parent drug and/or its related metabolites (sum-MRL substances) instead of single compounds (Danaher et al., 2007).

Their massive use in the last years has led into their accumulation in the environment, thus contaminating the water streams. European Water Framework Directive (Directive 2006/11/CE 4) has established a maximum concentration level (MCL) of $0.1 \mu \mathrm{g} \cdot \mathrm{L}^{-1}$ for most benzimidazole compounds present in natural waters, and a total concentration of all pesticides of $0.5 \mu \mathrm{g} \cdot \mathrm{L}^{-1}$. The need to determine low concentrations of these substances as well as matrix complexity means that analytical methods with high sensitivity, selectivity and resolution have to be applied to soil, sediment, water and other environmental samples. Elaborate sample preparation involving analyte isolation and enrichment is generally necessary before the final analysis, which is usually performed using gas chromatography (GC) or high-performance liquid chromatography (HPLC).

The selection of an adequate sample treatment protocol allowing to carry out a multiresidue determination of benzimidazole compounds is currently a challenge, due to their chemical properties. The development of highly sensitive methods for the multiresidue determination of benzimidazole compounds in environmental samples is desirable, and for that purpose a preconcentration step and appropriate instrumental techniques are usually required. In this sense, extensive sample cleanup or preconcentration procedures might be applied to the determination of a wide variety of benzimidazole compounds, and the use of highly selective detection methods (i.e. tandem mass spectrometry) is usually required for multiresidue analysis.

A large amount of effort has been invested in the past few decades to develop and validate analytical methodologies to quantify benzimidazole compounds and their metabolites in environmental samples at concentration levels below the legislated MCLs. 
In this chapter some methodologies for the determination of BFs in environmental samples are presented. Its scope is the coverage of the main aspects which are involved in their determination in environmental matrices: sample handling, extraction/preconcentration and determination. We will conclude with a general conclusion and notes on future perspectives.

\section{Environmental liquid samples preparation}

Contamination of natural waters by pesticides is one of the main environmental problems around the world because of the common use, persistence, bioaccumulation and toxicity of these pollutants. Determining the degree of ground and surface water contamination by these compounds is one of the fundamental aims of environmental analytical laboratories. To reach the low limits of detection is necessary the use of sensitive multi-residue methods for detecting and identifying these compounds, with the fewest number of intermediate step.

Sample preparation is one of the most important steps in a whole analytical process. The objective of the sample preparation is not only to isolate the target analytes from the samples, thus reducing or even eliminating the interferences originally present in the sample, but also simultaneously to concentrate the analytes to facilitate their determinations at low levels. Sample preparation gradually becomes a major part of analysis, capable of taking up to $80 \%$ of the total time of a complete analysis process. Different steps in the process, extraction, clean-up and detection play a key factor in the safety and accuracy of analysis.

\begin{tabular}{|c|c|c|c|c|}
\hline Name & Chemical structure & $\mathbf{K}_{\mathrm{oc}}$ & $\mathrm{pK}_{\mathrm{a} 1}$ & $\mathrm{pK}_{\mathrm{a} 2}$ \\
\hline $\begin{array}{c}\text { Albendazole } \\
\text { (ABZ) }\end{array}$ & & $2.2-2.92$ & 5.54 & 13.11 \\
\hline Benomyl & & 1.4 & 4.48 & \\
\hline $\begin{array}{l}\text { Carbendazim } \\
\text { (MBC) }\end{array}$ & & $1.29-1.69$ & 5.52 & 13.09 \\
\hline $\begin{array}{c}\text { Fenbendazole } \\
\text { (FBZ) }\end{array}$ & & $3.07-4.01$ & 5.12 & 12.72 \\
\hline $\begin{array}{c}\text { Fuberidazole } \\
\text { (FDZ) }\end{array}$ & & 2.71 & 4.0 & \\
\hline
\end{tabular}




\begin{tabular}{|c|c|c|c|c|}
\hline Name & Chemical structure & $\mathbf{K}_{\mathrm{oc}}$ & $\mathrm{pK}_{\mathrm{a} 1}$ & $\mathrm{pK}_{\mathrm{a} 2}$ \\
\hline $\begin{array}{c}\text { Mebendazole } \\
\text { (MBZ) }\end{array}$ & & $2.44-2.52$ & 4.13 & 11.79 \\
\hline $\begin{array}{c}\text { Oxibendazole } \\
\text { (OXI) }\end{array}$ & & $1.86-2.63$ & 6.26 & 13.78 \\
\hline $\begin{array}{c}\text { Oxfendazole } \\
\text { (OFZ) }\end{array}$ & & $1.88-2.13$ & 4.13 & 11.79 \\
\hline $\begin{array}{c}\text { Parbendazole } \\
\text { (PAR) }\end{array}$ & & $1.86-2.63$ & 5.99 & 13.53 \\
\hline $\begin{array}{l}\text { Thiabendazole } \\
\text { (TBZ) }\end{array}$ & & $1.58-1.76$ & 5.82 & 12.79 \\
\hline Triclabendazole & & $4.90-6.66$ & 5.31 & 12.91 \\
\hline
\end{tabular}

Table 1. Chemical structures and calculated properties of some benzimidazole fungicides (BFs) (Danaher et al., 2007)

Because the low concentration levels in environmental waters, an extraction and preconcentration step is usually required. First extraction method was liquid-liquid extraction (LLE) with conventional organic solvent (Blanchflower et al. 1994; Fernández et al., 2001). However, LLE suffers from the disadvantages of being time-consuming, expensive and requiring large volumes of both samples and toxicity. Other methods, like solid phase extraction (SPE) (Picón et al., 2000; Garrido et al., 2003; Moral et al., 2006), online supported liquid membrane (SLME), microporous membrane liquid-liquid extraction (MMLLE) (Sandahl et al., 2000), cloud point extraction (CPE) (Halko et al., 2004) and solid phase microextraction (SPME) (López Monzón et al., 2007) have been proposed to extract and concentrate BFs from aquatic environments. 
In recent years, solid phase extraction (SPE) has widely been applied for the analysis of different pesticides in water samples, owing to the high enrichment factors achievable by this methodology using the high breakthrough volumes of materials such as $\mathrm{C}_{18}$ (Picón et al., 2000; Zamora et al., 2003; Garrido Frenich et al., 2003), polystyrenedivinylbenzene (Guenu et al., 1996), ethylvinylbenzene-divinylbenzene (JunkerBuchheit, 1996), polystyrene (Shimamura et al., 1998) and active carbon (Jeannot et al., 2000). In this sense, Guenu et al. used precolumns packed with PS-DVB sorbents for the on-line determination of very polar pesticides, including carbendazim (Guenu et al., 1996). The evaluation of the PS-DVB sorbent was first carried out by measuring the recoveries using off-line extraction with a 20 mg PS-DVB cartridge and percolating drinking and river water both spiked with $0.1 \mu \mathrm{g} \cdot \mathrm{L}^{-1}$ of each pesticide Limits of detections (LODs) were at the $0.05-0.3 \mu \mathrm{g} \cdot \mathrm{L}^{-1}$ level in surface waters for different polar pesticides.

Other authors used $\mathrm{C}_{18}$ extraction cartridges for extracting carbendazim, fuberidazole and thiabendazole from water samples obtaining LODs between 0.001 to $0.125 \mu \mathrm{g} \cdot \mathrm{L}^{-1}$. Satisfactory predictions ranging from 102 to $114 \%$ for carbendazim, 96 to $115 \%$ for fuberidazole and 90 to $107 \%$ for thiabendazole were sufficiently low to determine pesticide residues in water samples (Picón et al., 2000; Garrido Frenich et al., 2003). SPE requires large volumes of sample $(>200 \mathrm{~mL})$ and organic solvent $(12-50 \mathrm{~mL})$ and BFs losses occur during the evaporation of the extracts (Guenu et al., 1996).

Recent developments in SPE field are mainly related to the use of new sorbent materials. Molecularly imprinted polymers (MIPs) have proven to be a very valuable technique for selective solid-phase extraction of the template molecule and structurally related compounds. The inherent selectivity of the molecular recognition of these materials allows a high degree of sample clean-up to be achieved (Baghianni et al., 2006; Pichón et al., 2006). Additionally, MIPs have also been used for sample enrichment for the determination of a wide range of analytes. MIPs have successfully been applied as highly selective sorbents for the extraction of benzimidazole compounds in an organic media (de Prada et al. 2007; Cacho et al., 2008; Turiel et al., 2005). However, coelution of the different benzimidazole compounds has been described when using these imprinted polymers as selective stationary phases (Cacho et al., 2009). For that, development of molecularly imprinted solid-phase extraction (MISPE) procedure permit the enrichment of benzimidazoles fungicides, based on an on-line sample enrichment of water samples by means of an imprinted polymer, synthesized by precipitation polymerization using thiabendazole as template molecule, methacrylic acid as functional monomer, and divinylbenzene as cross-linker. Initial experiments carried out by solid-phase extraction on cartridges demonstrated a clear imprint effect for thiabendazole, as well as the ability of the imprinted polymer to selectively rebind several benzimidazole compounds. The developed methodology has been applied to the quantification of thiabendazole, carbendazim, and benomyl in river, tap and well water samples within a single analytical run at concentration levels below the legislated maximum concentration levels. In this sense, obtained detection limits were of $2.3-5.7 \mathrm{ng} \cdot \mathrm{L}^{-1}$ for the analysis of benzimidazole fungicides in different water matrices. Recoveries obtained for the determination of benzimidazole fungicides in spiked samples ranged from $87 \%$ to $95 \%$, with relative standard deviations (RSD s) below 5\% in all cases (Zamora et al, 2009).

López-Monzón et al. (2007) established a suitable and sensitive method for simultaneous determination of BFs (carbendazim, benomyl, fuberidazole and thiabendazole) in water samples using solid phase microextraction (SPME). Authors evaluated the efficiency of extraction of these compounds on different kinds of fibres and optimized several SPME 
conditions: extraction time, ionic strength, extraction temperature and desorption time. The optimized SPME procedure was used for extraction and determination of these compounds in different environmental water samples (sea, sewage, and ground waters). A Carboxenpolydimethylsiloxane (CAR-PDMS) fibre was the optimum coating for extraction of these targets. Obtained recoveries ranged from 80.6 to 119.6 with RSDs below 9\% and limits of detection between 0.03 and $1.3 \mathrm{ng} \mathrm{mL}^{-1}$ for the different analytes. A chromatogram of this process is shown in Figure 1.
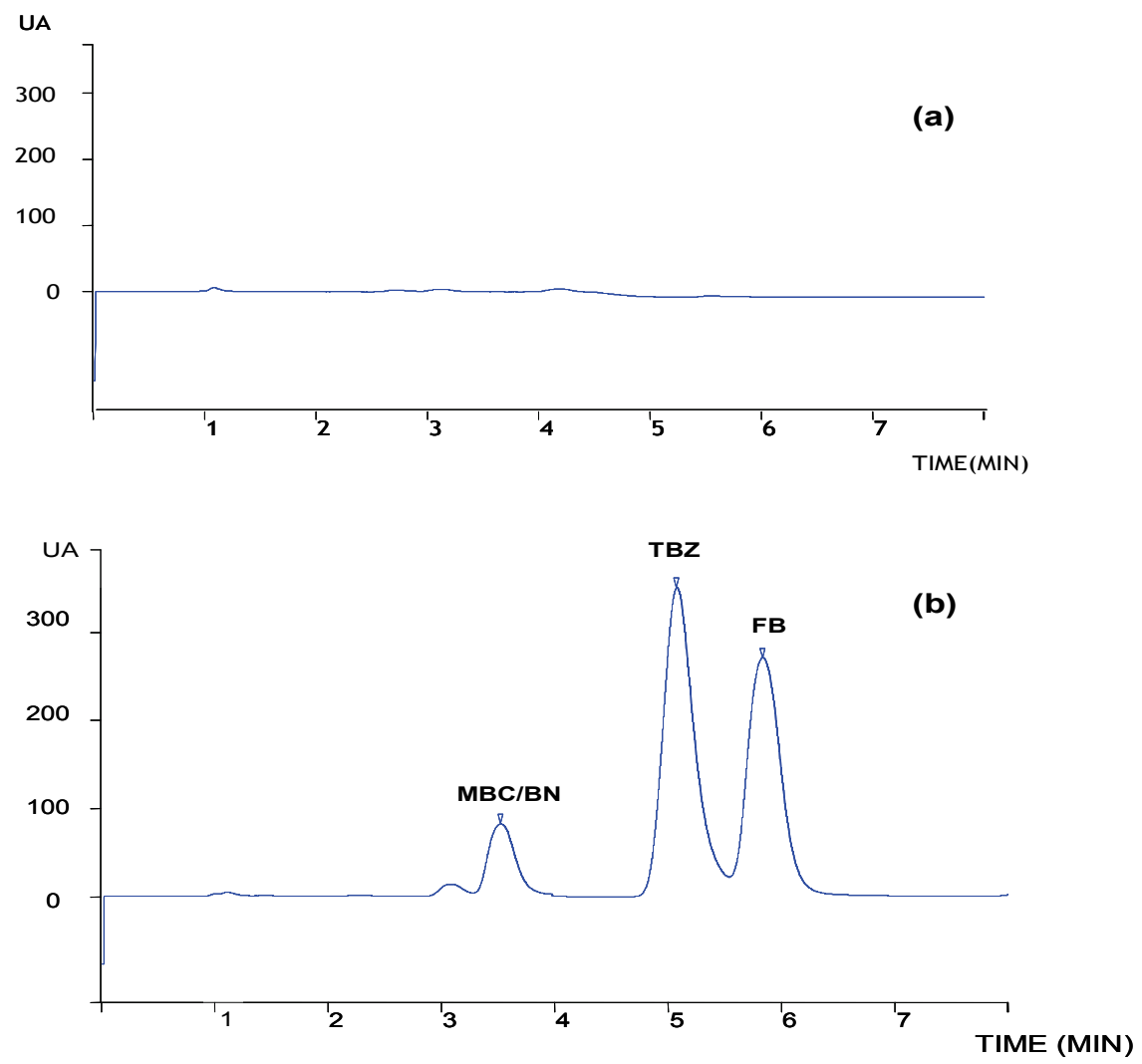

Fig. 1. Obtained chromatogram for a blank sample (a) and for the extract of benzimidazole fungicides from a spiked seawater sample (b) under optimum SPME extraction (LópezMonzón et al., 2007).

Extraction process like microporous membrane liquid-liquid extraction (MMLLE) and supported liquid membrane extraction (SLME) have been demonstrated to be efficient for sample preparation. MMLLE is a two-phase aqueous-organic solvent system and SLM a three phase aqueous-organic solvent-aqueous system, which leads to more selective extraction. All of them require lower amount of sample $(4-20 \mathrm{~mL})$ and organic solvent. An inconvenient of these procedures is time-consuming although enrichment rates of 0.6 times $\mathrm{min}^{-1}$ by SLME and 2.7 times $\mathrm{min}^{-1}$ by MMLLE have been reported (Sandahl et al., 2000) and SPME takes more than $1 \mathrm{~h}$ to obtain a concentration factor of 80 (López Monzón et al., 2007). 
Other pre-treatment method to extract and preconcentrate BFs in liquid samples is cloudpoint extraction (CPE). The cloud point phenomenon occurs when micellar solutions of nonionic or zwitterionic surfactants are heated above certain temperature, referred to as cloud point temperature, and they become turbid. At the cloud point, the surfactant solution undergoes phase separation into a surfactant-rich liquid phase and an almost micelle-free dilute solution whose concentration is equal to or lower than the critical micelle concentration. Obtained small volume of the surfactant-rich phase permitting extraction schemes to be designed allows us to preconcentrate and extract the analytes in one step, prior to liquid chromatographic analysis. CPE using non-ionic surfactant such as POLE and Genapol X-080 provides good extraction efficiency of different BFs in environmental liquid samples (Halko et al., 2004). The limit of detection (LOD) were $6 \mathrm{ng} \mathrm{mL}^{-1}$ for carbendazim, ng mL-1 benomyl, $0.15 \mathrm{ng} \mathrm{mL}^{-1}$ for thiabendazole and $0.01 \mathrm{ng} \mathrm{mL}^{-1}$ for fuberidazole in both surfactants. Obtained recoveries in spiked water samples ranged from $68 \%$ to $94 \%$ for Genapol and from $68 \%$ to $96 \%$ for POLE.

Other techniques like liquid phase microextraction, LPME (a small amount of a waterimmiscible solvent and an aqueous phase containing the analytes of interest) have emerged as an attractive alternative for sample preparations because of its simplicity, effectiveness, low cost, minimum use of solvents and excellent sample cleanup ability. Different configurations of this technique have recently emerged, including static LPME, dynamic LPME, single-drop LPME and hollow fiber-based liquid-phase microextraction, HF-LPME (extracting phase is placed inside of a porous hydrophobic hollow fiber) (Psillakis et al.,2002; Psillakis et al., 2003; Rasmussen et al, 2004; Pedersen-Bjergaard et al., 2005). However, several disadvantages, such as the instability of liquid drop in single-drop LPME, air bubbles formation in HF-LPME, long analysis time and relatively low precisions, are often encountered for such techniques. Very recently, a novel microextraction technique, named dispersive liquid-liquid microextraction (DLLME), based on dispersion of tiny droplets of the extraction solvent within the aqueous solution has been developed by Assadi and coworkers (Rezaee et al., 2006; Berijani et al., 2006; Fattahi et al., 2007). DLLME is a miniaturized LLE that uses microliter volumes of the extraction solvent. This method was applied to extract carbendazim and thiabendazole in water and soil samples using $80.0 \mu \mathrm{L}$ of $\mathrm{CHCl}_{3}$ as extraction solvent (Wu et al., 2009). Obtained limits of detection for MBC and TBZ were 0.5 and $1.0 \mathrm{ng} \mathrm{mL}^{-1}$ for liquid samples and 1.0 and $1.6 \mathrm{ng} \cdot \mathrm{g}^{-1}$ in solid samples, respectively.

Studies on the use of surfactant-coated mineral oxides columns for SPE have demonstrated these new sorbent materials to be a promising tool for the extraction/preconcentration of organic compounds in a wide polarity range (Merino et al., 2004; Moral et al., 2005). Adsorption of ionic surfactants on mineral oxides is a cooperative process; firstly, a monolayer of surfactant (i.e. hemimicelles) is formed with the surfactant head-group facing towards the oxide surface and its hydrocarbon tail-groups protrude into solution, interacting laterally between them. After that, surfactant adsorption occurs through hydrophobic interactions between hydrocarbon tail-groups, which results in the formation of discrete surface aggregates termed admicelles. Because of the amphiphilic character of surfactants, admicelles are aggregates in which there are regions of different polarity, acidity, etc. This feature makes these aggregates extremely versatile extractants because of the number of interactions they can establish with analytes. This type of process have been used for carbendazim, thiabendazole and fuberidazole preconcentration in water samples (Moral et al., 2006). Recently, Moral et al. (2009) have used supramolecular solvents based 
on vesicles of decanoic acid as a good extractant of benzimidazolic fungicides from natural waters. The high concentration of decanoic acid in the extractant phase and the capability of solubilisation of the vesicles permited the favourable partition of analytes from environmental water using a quite low volume of supramolecular solvent $(100 \mu \mathrm{L})$. Actual concentration factors around 150-200 are easily obtained using a single-step extraction without the need of solvent evaporation. Equilibrium conditions are rapidly established, the whole extraction takes about $20 \mathrm{~min}$ and several samples can be simultaneously extracted. The proposed method provided detection limits for the determination of CBZ, TBZ and FBZ in natural waters of 32,4 and $0.1 \mathrm{ng} \cdot \mathrm{L}^{-1}$, respectively, and a precision, expressed as relative standard deviation of $5.5 \%$ for CBZ, $4.0 \%$ for TBZ and $2.5 \%$ for FBZ.

\section{Environmental solid samples preparation}

Analytical methods for the determination of BFs in soil are scarce in the available scientific literature. Traditional methods employ large volumes of solvents under aggressive shaking and/or temperature conditions. The most frequently used methods for the extraction of organic compounds from soils are Soxhlet or ultrasonic extraction. The newer extraction techniques, such as supercritical fluid extraction (SFE) (Van der Velde et al., 1992; Snyder et al, 1993; Ling and Liao, 1996), pressurized liquid extraction (PLE) (Mogadati et al., 1999) and microwave-assisted extraction (MAE), are very attractive because they are faster, use much smaller amounts of solvents and are environmentally friendly techniques.

SFE uses a solvent in its supercritical state. This technique is attractive because it is fast, uses small amounts of solvent and commercially available SFE systems allow sample extraction in unattended operations. PLE is done in a closed-vessel at elevated temperatures and pressures. The higher temperature at which the extraction is conducted increases the capacity of the solvent to solubilise the analyte, and the higher pressure increases the diffusion rate into the pores of the matrix, thus facilitating the mass transfer of the analyte into the extracting solvent.

A method based on the sonication of soil samples placed in small columns (sonicationassisted extraction in small columns, SAESC) has been developed for the rapid and sensitive analysis of herbicides and insecticides in soil (Sánchez-Brunete et al., 1998; Castro et al., 2001). In 2002, Sánchez-Brunete et al. published a method for the simultaneous determination of fungicides in soil. The method is simple and uses low volumes of ethyl acetate as extracting solvent, reducing the human exposure to toxic solvents and the environmental impact of the analytical procedure although they did not include BFs in their work ( Sánchez-Brunete et al., 2002).

In the last few years, there has been an increase in the number of procedures using microwave energy to extract organic compounds from environmental matrices. Microwaveassisted extraction (MAE) is a process of using microwave energy to heat solvent in contact with a sample in order to obtain partition of analytes from the sample matrix into the solvent (Shu et al., 2003; Ramil Criado et al., 2003). In comparison with other conventional methodologies, such as Soxhlet extraction, MAE requires less energy, shorter analysis periods and the use of smaller solvent volume of analysis. Coscollá et al. (2009) developed a confirmatory and rapid procedure for extraction of different pesticides, including thiabendazole and carbendazim, in PM 2.5 particles by MAE using ethyl acetate. Recoveries ranged from 72 to $109 \%$ and the limit of quantification (LOQ) of $6.5 \mathrm{pg} \mathrm{m}^{-3}$ were obtained for this method. 
The use of micellar media as alternative to conventional organic solvents in the MAE procedure could offer important advantages such as safety, simplicity, lower toxicity, lower cost and greater compatibility with the aqueous organic mobile phase in the liquid chromatography (LC) separation process. This combination, called microwave-assisted micellar extraction (MAME) has been applied to the extraction of different compounds from solid matrices (Padrón-Sanz et al., 2002; Eiguren Fernández et al., 2001; Mahugo-Santana et al., 2004; Padrón Sanz et al., 2005). Among the advantages of the MAME are reduced volumes of extractant, low cost and reduced toxicity in comparison to organic solvents. Moreover, MAME reduce analysis time compared with conventional Soxhlet extraction.

In this sense, a MAME procedure for benomyl (BNM), carbendazim (MBC), thiabendazole (TBZ) and fuberidazole (FDZ) in soil samples was published by Halko et al. (2006). MAME extraction is influenced by different factors which must be controlled in order to obtain satisfactory results. The surfactant concentration, $\mathrm{pH}$ of solution, irradiation power and extraction time were studied and optimized using a factorial design. MAME using non-ionic surfactants, such as POLE and Genapol X-080 provides good extraction efficiency (between $71-105 \%$ ) of the studied fungicides and LODs between $0.02-0.6 \mu \mathrm{g} \cdot \mathrm{g}^{-1}$ for FDZ and TBZ and $25-30 \mu \mathrm{g} \cdot \mathrm{g}^{-1}$ for MBC/BNM. MAME is an alternative not only to classical extraction such as Soxhlet extraction, but also to MAE.

\section{Detection and determination methods}

Numerous analytical methods have been reported for quantitation of benzimidazole fungicides in different matrices based on spectrophotometry (Chiba, 1977), fluorimetry (Zamora et al. 2003; Cuesta et al. 2003), phosphorimetry (Salinas y et al. 2005), electrochemical (Huebra et al. 2000), enzyme-linked immuno-sorbent assay (Itak et al. 1993), gas chromatography-mass spectrometry (Lesueur et al. 2008), although is routinely carried out by high performance liquid chromatography coupled with ultraviolet (Melo et al. 2005; Singh et al. 2007; Prousalis et al. 2004), fluorescence (Moral et al. 2006; Hu et al. 2008), and mass spectrometry (Radisic et al. 2009) detectors. These methods have many advantages of high sensitivity and accuracy and some of them have been adopted by regulatory agencies. In environmental samples, flow injection analysis (FIA) coupled with chemiluminescence (CL) is a well established technique for the ultra-trace analysis of a variety of compounds in diverse matrices using various CL reagents including benzimidazole fungicides (Fletcher et al. 2001). FIA-CL method for the determination of carbendazim has been reported (Liao and Xie 2006), which is based on the enhancement of CL reaction of luminol and hydrogen peroxide $\left(\mathrm{H}_{2} \mathrm{O}_{2}\right)$ by a carbendazim in sodium hydroxide-sodium dihydrogen phosphate medium ( $\mathrm{pH}$ 12.6). This method was applied to the determination of carbendazim in tapwater samples with a linear range of $0.02-2 \mathrm{mg} \mathrm{mL}^{-1}$ and a limit of detection of $7.24 \mathrm{ng} \mathrm{mL}^{-1}$. Recently, a simple FIA-CL method for the determination of BFs (fuberidazole, benomyl, and carbendazim) was developed because CL emission was observed when the reaction of $\mathrm{Cu}^{+2}$ and $\mathrm{H}_{2} \mathrm{O}_{2}$ was carried out in an alkaline $\mathrm{Na}_{2} \mathrm{CO}_{3}$ solution without CL reagent. On the addition of a trace amount of BFs to a mixture of $\mathrm{Cu}^{+2}-\mathrm{H}_{2} \mathrm{O}_{2}-\mathrm{Na}_{2} \mathrm{CO}_{3}, \mathrm{CL}$ emission was enhanced (Waseem et al. 2007, Waasem et al., 2010).

Gas chromatography (GC) determination of BFs is difficult because their thermal instability do not permit their analysis directly unless they are derived into thermally stable derivatives. However, TBZ and TCB are sufficiently volatile to allow their determination by GC without derivatisation. Some reseachers have found GC coupled to mass spectrometry 
useful for confirmation of the presence of benzimidazole residues. However, GC-MS procedures usually require derivatisation of residues to induce volatility and allow the generation of suitable MS spectra for confirmatory analysis and, as a result, have been largely been replaced by LC-MS/MS. Some quantitative GC methods have been developed by some researchers to determine the presence of benzimidazole fungicides in different matrices including soils (Castro et al., 2001; Leuseur et al., 2008).

\subsection{Liquid chromatography based detection systems 4.1.1 Detection by UV and fluorescence.}

Spectrometric methods are suitable for quantitation of high levels of benzimidazole residues in different matrices. However, when quantitation of benzimidazoles in the low $\mu \mathrm{g} \mathrm{kg}^{-1}$ range and greater selectivity is required, chromatographic separation of residues prior to spectrometric detection is generally required.

To analyze the growing number of modern pesticides and their degradation products, which are generally thermolabile, polar and non-volatile, the analytical methods employing gas chromatography in combination with specific detectors or coupled with mass spectrometry (MS) are not reliable without a time-consuming derivatization step, which itself can generate interferences. Consequently, liquid chromatography (LC) combined with diode array detection (DAD) has been used increasingly in recent years as a complementary method for pesticide analysis.

Benzimidazole fungicides like albendazole (ABZ), benomyl (BNM), carbendazim (MBC), fenbendazole (FBZ), fuberidazole (FDZ) and thiabendazole (TBZ) have been used from Cacho et al. (2009) to optimise a MISPE method coupled to HPLC-UV. These compounds were monitored at 200 and $240 \mathrm{~nm}$. LODs obtained were between 0.03-0.09 $\mathrm{ng} \mathrm{mL}^{-1}$ depending of the compound. The obtained detection limits were below the legislated MCL in all cases.

Zamora et al. (2009) coupled the molecularly imprinted solid-phase extraction (MISPE) procedure to a HPLC-UV system to determine benomyl (BNM), carbendazim (MBC) and thiabendazole (TBZ) in river, tap and well waters. LODs obtained were between 2.5-5.0 ng $\mathrm{L}^{-1}$ depending of the studied compound.

A number of researchers have developed different methods for determination of benzimidazole residues using HPLC coupled to fluorescence detection. Fluorescence detection offer sensitivity and selectivity to methods, potentially reducing the need for extensive sample clean-up.

Moral et al. (2006) used supramolecular sorbents for the extraction/preconcentration of BFs: carbendazim (CBZ), thiabendazole (TBZ) and fuberidazole (FDZ), and to evaluate their applicability for the analysis of natural waters. Same authors optimized supramolecular solvent-based extraction and the fluorescence measurements were performed at 286/320 (time $=0-9 \mathrm{~min}$ ) and 300/350 $\mathrm{nm}$ (time 9-15 min) excitation/emission wavelengths, respectively. These wavelengths were selected on the basis of the excitation and emission spectra obtained for each of the target analytes solubilized in the mobile phase. Obtained detection limits were $0.032 \mathrm{ng} \mathrm{mL}^{-1}$ for CBZ, $0.004 \mathrm{ng}^{\mathrm{mL}-1}$ for TBZ and $0.0001 \mathrm{ng} \mathrm{mL}^{-1}$ for FBZ (Moral et al., 2009).

Wu et al. (2009) used a HPLC-fluorescence detection for the determination of carbendazim (MBC) and thiabendazole (TBZ) in water and soil samples obtaining good results. For water samples, LODs were $0.5 \mathrm{ng} \mathrm{mL}-1$ for $\mathrm{MBC}$ and $1.0 \mathrm{ng} \mathrm{mL}^{-1}$ for TBZ. In the case of the soil samples, LODs were $1.0 \mathrm{ng} \cdot \mathrm{g}^{-1}$ for MBC and $1.6 \mathrm{ng} \cdot \mathrm{g}^{-1}$ for TBZ. 
LC-fluorescence could be applied as an alternative technique to allow determination and confirmation of selected benzimidazole residues. However, not all benzimidazole residues fluoresce naturally. For that, other methods like LC-MS for determination and confirmation of BFs will be reviewed for environmental samples.

\subsubsection{Detection by mass-spectrometry.}

In the last years, liquid chromatography-mass spectrometry (LC-MS) techniques have advanced in their sensitivity, specificity and reliability. Progress is mostly due to development of hyphenated LC-tandem MS techniques, which are today the methods of choice for the determination of trace organic analytes in environmental samples. Swift growth in the use of LC-MS/MS for the analysis of organic contaminants in environmental matrices has been compelled by the need for high-quality data on their occurrence in the environment at very low concentration levels (Petrovic et al., 2010). Application of tandem mass spectrometry (MS/MS) has resulted in improved determination and confirmation of polar compounds in different environmental matrices.

LC should preferably be applied for the analysis of organic micropollutants only when using tandem MS because this combination is able to produce fragment ions that are necessary for the explicit identification of the analytes (Reddersen \& Heberer 2003). LCMS/MS allows separation and detection of compounds having the same molecular mass but different product ions, even if they co-elute. MS/MS detection is therefore preferred for increased analytical sensitivity and selectivity in complex water matrices (Díaz-Cruz \& Barceló 2005). The most commonly used LC-MS/MS interfaces are atmospheric pressure ionization technologies, such as ESI and atmospheric pressure chemical ionization (APCI). ESI is well suited for the analysis of polar compounds, whereas APCI is very effective in the analysis of medium-polarity and low-polarity substances (Radjenovic et al. 2007). Optimization of MS parameters, including cone voltage and collision energy, is performed via flow injection analysis for each compound of interest (Gros et al. 2006; Baugros et al. 2008).

As discussed above, the majority of the analytical procedures published for determining benzimidazoles have been developed based on high performance liquid chromatography (HPLC) because of the polar nature (zwitterion) and thermal lability. In recent years, HPLCbased method combined with sensitive mass spectrometric detection (LC-MS) or versatile tandem mass spectrometry (LC-MS/MS) amenable to multiple reaction monitoring (MRM) has become the analytical tool of choice for simultaneous sensitive quantification and confirmation of a wide range of target fungicides and the structurally related metabolites in complex matrices (Wang et al., 2007; Economu et al., 2009).

Balizs (1999) described the determination of benzimidazole residues including TBZ, ABZ, MBZ, FDZ, OFZ and OXI using LC-MS and LC-MS/MS optimizing, initially, by direct infusion of a standard solution of each benzimidazole. After that, BFs residues were separated using ammonium acetate and acetic acid in the mobile phase to produce protonated molecular ions. Obtained mass spectra were simple and consisted of a few fragments of the protonated molecular ion $[\mathrm{M}+\mathrm{H}]^{+}$. Guo et al. (2010) included BNM, MBC and FDZ to develop their multi-residue procedure for effective extraction of BFs for analysis by LC-MS/MS. Table 2 shows the individual precursor to product ion transitions specific to different analytes including precursor ion $\left(Q_{1}\right)$ and product ion $\left(Q_{3}\right)$ obtained for these authors. These methods were applied in muscle, eggs and agricultural products. Balizs (1999) obtained detection limits between 3 and $20 \mu \mathrm{g} \mathrm{kg}^{-1}$. Gou et al. (2001) improved these 
LODs because they used a QuEChERs process (salting-out liquid-liquid partitioning extraction followed by dispersive solid phase extraction), obtaining values between $0.15-0.30 \mathrm{ng} \cdot \mathrm{g}^{-1}$.

\begin{tabular}{|c|c|c|}
\hline Compound & $\mathbf{Q}_{\mathbf{1}}$ & $\mathbf{Q}_{\mathbf{3}}$ \\
\hline ABZ & 266 & 233 \\
\hline BNM & 291 & 192 \\
\hline MBC & 192 & 132 \\
\hline FBZ & 300 & 268 \\
\hline FDZ & 185 & 92 \\
\hline MBZ & 296 & 264 \\
\hline OXI & 250 & 176.1 \\
\hline OFZ & 316.2 & 159.1 \\
\hline TCB & 359 & 343 \\
\hline TBZ & 202 & 131 \\
\hline
\end{tabular}

Table 2. Typical ions of the BFs in LC-MS and LC-MS/MS (from Balizs (1999) and Gou et al. (2010)).

To our knowledge, there not papers exclusively related with determination of BFs in environmental samples using LC-MS/MS. However, there are some published multiresidue methods that include benzimidazole compounds. For example, Jeannot et al. (2000) used LC-MS for the multi-residue analysis of pesticides in surface waters among those included CBZ. Limit of detection for CBZ was $6 \mathrm{ng} \cdot \mathrm{L}^{-1}$.

It is important to remember that the analysis is complicated by the instability of several benzimidazoles during analytical processes. The accepted methods have been well documented for measuring BNM or/and tiophanate-methyl as MBC or other breakdown products (Di Mucio et al., 1995; Singh et al., 2007), which entails a complete or quantitative conversion of the parent molecule to its stable metabolite prior to analysis. The major disadvantage of such a total residue approach is the conversion into other transformation products, which might also be marker species already present as their natural occurrence in the sample (Danaher et al., 2007). To overcome this problem, successive efforts have been made in developing methodology for direct determination of BNM or other benzimidazoles like tiophanate-methyl in the intact form, by addition of decomposition retardants (Chiba et al., 1977), or by virtue of the enhanced stabilities in strongly acidic aqueous media or at low temperatures (García Reyes et al., 2004; Cacho et al., 2009).

\subsection{Other methods}

Bioassays have been used to detect benzimidazole residues in food but are more routinely used to evaluate the potency of anthelmintic substances. In the other hand, immunochemical technologies offer a number of advantages in environmental analysis (e.g., reduced time of analysis, low limits of detection (LODs) with sensitivity in many cases comparable to conventional chromatographic techniques, high throughput of samples, costeffective detection, and adaptability to field use). However, one of the most important advantages is their possible automation that can be adapted to work remotely, on-line or atsite (Farré et al., 2007).

Within the most representative immunochemical technologies applied to environmental analysis are enzyme-based immunoassays which usually use a change in color or emission 
of light to measure the concentration of the analyte. This technique offers numerous advantages over other immuno-techniques because their signal is amplified by forming a great number of product molecules and they are widely used, especially those based on heterogeneous conditions, such as enzyme-linked immunosorbent assays (ELISAs). Although there have been a number of significant applications of ELISA technology in the area of benzimidazole analysis in biological matrices, there not significant works related with environmental samples. However, Thomas et al. (1996) developed a method that incorporates many of the advantages of immunochemical techniques into a format more suitable for routine analytical laboratories. It is high-performance immunoaffinity chromatography (HPIAC). In HPIAC, the antibody is immobilized onto a high-performance liquid chromatographic support and used as an affinity ligand to extract the target analyte from an aqueous sample injected onto the HPIAC column. Any material not specifically recognized by the antibody passes through the column to waste, while the target analyte remains bound to the immobilized antibody until the mobile phase conditions are changed to disrupt the antibody analyte interaction. The analyte is subsequently eluted and detected. These authors described the application of HPIAC coupled on-line with either HPLC-DAD or HPLC-MS to determine the fungicide carbendazim in water samples and they compared the obtained results with the ELISA technique. LODs were better with HPIAC methods (0.025 ng $\mathrm{mL}^{-1}$ for HPLC-MS and $0.075 \mathrm{ng} \mathrm{mL}^{-1}$ for HPLC-DAD) than ELISA method (0.10 ng $\left.\mathrm{mL}^{-1}\right)$.

Table 3 presents a summary of the most representative methods to extract and determine $\mathrm{BFs}$ in terms of the sample matrix and analytical parameters.

\begin{tabular}{|c|c|c|c|c|c|}
\hline Analytes & Samples & Extraction & $\begin{array}{c}\text { Determination } \\
\text { tecnique }\end{array}$ & $\begin{array}{c}\text { Analytical } \\
\text { Parameters }\end{array}$ & Ref. \\
\hline CBZ & soil & - & HPLC-UV/Vis & $\begin{array}{c}\text { RSDs: } 4.5 \% \\
\text { LODs: } 0.3 \mu \mathrm{g} \mathrm{mL}^{-1}\end{array}$ & $\begin{array}{c}\text { Huebra } \\
\text { et al. } \\
(2000)\end{array}$ \\
\hline CBZ & water & SLM, MMLLE & HPLC-UV & $\begin{array}{c}\text { RSDs: }<5 \% \\
\text { LODs: } 0.1-0.5 \\
\mu \mathrm{gL}^{-1}\end{array}$ & $\begin{array}{c}\text { Sandahl } \\
\text { et al. } \\
(2000)\end{array}$ \\
\hline $\begin{array}{c}\text { CBZ, } \\
\text { FDZ, TBZ }\end{array}$ & water & SPE & $\begin{array}{l}\text { cross-section } \\
\text { fluorimetry }\end{array}$ & $\begin{array}{c}\text { Recovery: } 90-120 \% \\
\text { RSDs: } 1.5-4.8 \% \\
\text { LODs: } 0.017-0.29 \\
\text { ng } \mathrm{mL}^{-1}\end{array}$ & $\begin{array}{l}\text { Zamora } \\
\text { et al. } \\
(2000)\end{array}$ \\
\hline $\begin{array}{c}\text { CBZ, } \\
\text { FDZ, TBZ }\end{array}$ & water & SPE & spectrofluorimetry & $\begin{array}{c}\text { Recovery: } 91-115 \% \\
\text { RSDs: } 0.02-4.0 \% \\
\text { LODs: } 0.1-100 \\
\mu \mathrm{g} \cdot \mathrm{L}^{-1}\end{array}$ & $\begin{array}{l}\text { Garrido } \\
\text { et al. } \\
(2002)\end{array}$ \\
\hline $\begin{array}{c}\text { CBZ, } \\
\text { FDZ, TBZ }\end{array}$ & water & SPE & $\begin{array}{l}\text { luminescence } \\
\text { spectrometer }\end{array}$ & $\begin{array}{c}\text { Recovery: } 97-109 \% \\
\text { RSDs: } 3.3-6.4 \% \\
\text { LODs: } 0.001-0.13 \\
\mu \mathrm{g} \cdot \mathrm{L}^{-1}\end{array}$ & $\begin{array}{l}\text { Zamora } \\
\text { et al. } \\
(2002)\end{array}$ \\
\hline $\begin{array}{c}\text { CBZ, } \\
\text { BNM, } \\
\text { FDZ, TBZ } \\
\end{array}$ & water & $\mathrm{CPE}$ & HPLC-Fluorescence & $\begin{array}{c}\text { Recovery: } 70-96 \% \\
\text { LODs: } 0.01- \\
6 \text { ng mL-1 }\end{array}$ & $\begin{array}{l}\text { Halko et } \\
\text { al. }(2004)\end{array}$ \\
\hline
\end{tabular}




\begin{tabular}{|c|c|c|c|c|c|}
\hline Analytes & Samples & Extraction & $\begin{array}{c}\text { Determination } \\
\text { tecnique }\end{array}$ & $\begin{array}{c}\text { Analytical } \\
\text { Parameters }\end{array}$ & Ref. \\
\hline FDZ & water & - & $\begin{array}{c}\text { fluorescence } \\
\text { spectrophosphorimeter }\end{array}$ & $\begin{array}{l}\text { RSDs: } 3.1 \% \\
\text { LODs: } 95 \text { ng } \cdot \mathrm{L}^{-1}\end{array}$ & $\begin{array}{l}\text { Salinas et } \\
\text { al. (2005) }\end{array}$ \\
\hline $\begin{array}{c}\text { CBZ, } \\
\text { BNM, } \\
\text { FDZ, TBZ }\end{array}$ & soil & MAME & HPLC-Fluorescence & $\begin{array}{c}\text { Recovery: 70-105 \% } \\
\text { LODs: 0.02-0.06 } \\
\mu \mathrm{g} \cdot \mathrm{g}-1 \\
25-30 \mu \mathrm{g} \cdot \mathrm{g}^{-1} \\
(\mathrm{MBC} / \mathrm{BNM}) \\
\end{array}$ & $\begin{array}{l}\text { Halko et } \\
\text { al. }(2006)\end{array}$ \\
\hline CBZ & soil & $\begin{array}{c}\text { ultrasonic } \\
\text { solvent } \\
\text { extraction, } \\
\text { QuECheRS, } \\
\text { PLE } \\
\end{array}$ & $\begin{array}{c}\text { GC-MS } \\
\text { HPLC-MS/MS }\end{array}$ & $\begin{array}{c}\text { RSDs: }<20 \% \\
\text { LODs: } 0.01 \mathrm{ng} \cdot \mathrm{g}^{-1}\end{array}$ & $\begin{array}{l}\text { Lesueur } \\
\text { et al. } \\
(2007)\end{array}$ \\
\hline $\begin{array}{c}\text { CBZ, } \\
\text { BNM, } \\
\text { FDZ, TBZ }\end{array}$ & water & SPME & HPLC-Fluorescence & $\begin{array}{c}\text { RSDs: }<9.0 \% \\
\text { LODs: } 0.03-1.3 \\
\text { ng } \mathrm{mL}^{-1}\end{array}$ & $\begin{array}{c}\text { López } \\
\text { Monzón } \\
\text { et al. } \\
(2007) \\
\end{array}$ \\
\hline \begin{tabular}{|c|} 
ABZ, \\
BNM, \\
FBZ, \\
FDZ, \\
CBZ, TBZ
\end{tabular} & $\begin{array}{l}\text { spiked river, } \\
\text { tap and well } \\
\text { water }\end{array}$ & MISPE & HPLC-DAD & $\begin{array}{c}\text { Recovery: } 89- \\
105 \% \\
\text { RSDs: } 2.1-6.7 \% \\
\text { LODs: } 0.03- \\
0.09 \mu \mathrm{g} \cdot \mathrm{L}^{-1} \\
\end{array}$ & $\begin{array}{l}\text { Cacho et } \\
\text { al. }(2009)\end{array}$ \\
\hline CBZ, TBZ & water, soil & LLME & HPLC-Fluorescence & $\begin{array}{c}\text { Recovery: 50.8- } \\
70.9 \% \\
\text { RSDs: } 3.5-6.8 \% \\
\text { LODs: } 0.5-1.0 \\
\mu \mathrm{g} \cdot \mathrm{L}^{-1} ; \\
1.0-1.6 \mathrm{ng} \cdot \mathrm{g}^{-1}\end{array}$ & $\begin{array}{c}\text { Wu et al. } \\
\text { (2009) }\end{array}$ \\
\hline $\begin{array}{c}\text { CBZ, } \\
\text { FDZ, TBZ }\end{array}$ & $\begin{array}{c}\text { river, } \\
\text { underground } \\
\text { water }\end{array}$ & $\begin{array}{l}\text { supramolecular } \\
\text { solid-phase } \\
\text { extraction }\end{array}$ & HPLC-Fluorescence & $\begin{array}{c}\text { RSDs: } 2-6 \% \\
\text { LODs: } 0.1-32 \text { ng } \mathrm{L}-\end{array}$ & $\begin{array}{r}\text { Moral et } \\
1 \text { al. (2009) }\end{array}$ \\
\hline $\begin{array}{c}\text { BNM, } \\
\text { CBZ, TBZ }\end{array}$ & water & MISPE online & HPLC-DAD & $\begin{array}{c}\text { Recovery: } 87-95 \% \\
\text { RSDs: }<5 \% \\
\text { LODs: } 2.3-5.7 \\
\text { ng } \cdot \mathrm{L}^{-1}\end{array}$ & $\begin{array}{c}\text { Zamora } \\
\text { et al. } \\
(2009)\end{array}$ \\
\hline
\end{tabular}

Abbreviations: RSD: Relative standard deviation, LOD: limit of detection, LC: liquid chromatography, GC: Gas chromatography, HPLC: high performance liquid chromatography, UV: Ultraviolet visible detection, PDA: Photodiodearray detection, MS: mass spectrometry, APCI: atmospheric pressure chemical ionisation, MIP: molecularly imprinted polymer, MISPE: Molecularly imprinted solid-phase extraction, ELISA: enzyme linked immunoassays, SPE: solid phase extraction; LLME: liquid-liquid microextraction; SPME: solid phase microextraction; MAME: Micellar assisted microwave extraction; CPE: cloud point extraction.

Table 3. Most representative methods to determine benzimidazole fungicides (BFs) in environmental samples. 


\section{Conclusions and future perspectives.}

This chapter describes the most relevant aspects which are involved in the determination of benzimidazole fungicides (BFs) in environmental samples. It is well known that sample preparation is one of the most critical steps in the determination of trace pollutants in different environmental matrices. In order to improve the quality of the analytical methods used, sample preparation techniques should be improved for this proposal. On the other hand, although some of the techniques presented in this overview are known and have been applied (HPLC with UV and/or fluoresence detection) to determine BFs in environmental samples, trends in this field should develop multi-residue methodology that allows the determination of the complete range of benzimidazole fungicides (BFs) in different environmental matrices in a single analysis. In this sense, advanced analytical methods have been developed and optimized with the aim of improving precision and sensitivity. LC-MS and LC-MS/MS have found more widespread application in environmental analysis offering more sensitive detection and increased confidence in reporting results. It should be desirable the development of specific methods for BFs in environmental samples using LCMS/MS combined with new sample treatments to apply to real environmental samples. Alternatively, HPLC coupled to UV and fluorescence detection in series may offer a low cost to LC-MS/MS and may be particularly effective in the optimization of sample treatments.

\section{References}

Baggiani C.; Anfossi L. \& Giovannoli C. (2006). Molecular imprinted polymers: Useful tools for pharmaceutical analysis. Current Pharmaceutical Analysis, 2 (3), 219-247, ISSN 1573-4129.

Balizs, G. (1999). Determination of benzimidazole residues using liquid chromatography and tandem mass spectrometry. Journal of Chromatography B: Biomedical Sciences and Applications, 727 ( 1-2), 167-177, ISSN 1387-2273.

Baugros, J.-B.; Giroud, B.; Dessalces, G.; Grenier-Loustalot, M.-F. \& Cren-Olivé, C. 2008. Multiresidue analytical methods for the ultra-trace quantification of 33 priority substances present in the list of REACH in real water samples. Analytica Chimica Acta, 607 (2), pp. 191-203, ISSN 0003-2670.

Blasco C.; Font G. \& Picó Y. (2005). Analysis of pesticides in fruits by pressurized liquid extraction and liquid chromatography-ion trap-triple stage mass spectrometry. Journal of Chromatography A, 1098 (1-2), 37-43, ISSN 0021-9673.

Berijani S.; Assadi Y.; Anbia M.; Hosseini M.R.M. \& Aghaee E (2006). Dispersive liquidliquid microextraction combined with gas chromatography-flame photometric detection. Very simple, rapid and sensitive method for the determination of organophosphorus pesticides in water. Journal of Chromatography A, 1123 (1), 1-9, ISSN 0021-9673.

Blanchflower W.J.; Cannavan A. \& Kennedy D.G. (1994). Determination of fenbendazole and oxfendazole in liver and muscle using liquid chromatography-mass spectrometry. Analyst , 119, (6) 1325-1328 ISSN 0003-2654.

Cacho C.; Schweitz L.; Turiel E. \& Perez-Conde C. (2008). Molecularly imprinted capillary electrochromatography for selective determination of thiabendazole in citrus samples. Journal of Chromatography A, 1179 (2), 216-223, ISSN 0021-9673. 
Cacho C. ; Turiel E. \& Perez-Conde C. (2009). Molecularly imprinted polymers: An analytical tool for the determination of benzimidazole compounds in water samples. Talanta, 78 (3), 1029-1035, ISSN 0039-9140.

Castro J.; Sánchez-Brunete C. \& Tadeo J.L. (2001). Multiresidue analysis of insecticides in soil by gas chromatography with electron-capture detection and confirmation by gas chromatography-mass spectrometry. Journal of Chromatography A, 918 (2), 371380, ISSN 0021-9673.

Chiba, M. 1977. A rapid spectrophotometric method for the simultaneous determination of intact benomyl and its degradation product, methyl 2-benzimidazolecarbamate $(\mathrm{MBC})$, in organic solvents and water. Journal of Agricultural and Food Chemistry, 25(2), 368-373, ISSN 0021-8561.

Cuesta, M. J.; Boque R. R.; Rius F. X.; Zamora D. P.; Galera M. M. \& Frenich A. G. 2003. Determination of carbendazim, fuberidazole and thiabendazole by threedimensional excitation-emission matrix fluorescence and parallel factor analysis. Analytica Chimica Acta, 491(1), 47-56, ISSN: 0003-2670.

Danaher M.; De Ruyck H.; Crooks S.R.H.; Dowing G. \& O'Keeffe M.. (2007). Review of methodology for the determination of benzimidazole residues in biological matrices. Journal of Chromatography B: Analytical Technologies in the Biomedical and Life Sciences, 845 (1), 1-37, ISSN: 1570-0232.

De Prada A.G.V.; Loaiza O.A.; Serra B.; Morales D.; Martinez-Ruiz P.; Reviejo A.J. \& Pingarron J.M. (2007). Molecularly imprinted polymer solid-phase extraction coupled to square wave voltammetry at carbon fibre microelectrodes for the determination of fenbendazole in beef liver. Analytical and Bioanalytical Chemistry, 388 (1), 227-234, ISSN 1618-2642.

Directive 2006/11/EC of the European Parliament: pollution caused by certain dangerous substances discharged into the aquatic environment of the Community.

Economou A; Botitsi H.; Antoniou S. \& Tsipi D. (2009). Determination of multi-class pesticides in wines by solid-phase extraction and liquid chromatography-tandem mass spectrometry. Journal of Chromatography A, 1216 (31), 5856-5867, ISSN 00219673.

Eiguren Fernández, A.; Sosa Ferrera, Z. \& Santana Rodríguez, J.J (2001). Application of microwave-assisted extraction using micellar media to the determination of polychlorinated biphenyls in marine sediments. Analytica Chimica Acta, 433, 237244, ISSN 0003-2670.

Farré, M.; Kantiani, L. \& Barceló, D. (2007). Advances in immunochemical technologies for analysis of organic pollutants in the environment. TrAC - Trends in Analytical Chemistry, 26 (11), 1100-1112, ISSN 0165-9936.

Fattahi N.; Assadi Y.; Hosseini M.R.M. \& Jahromi E.Z. (2007). Determination of chlorophenols in water samples using simultaneous dispersive liquid-liquid microextraction and derivatization followed by gas chromatography-electroncapture detection. Journal of Chromatography A,1157, 23-29, ISSN 0021-9673.

Fernández M.; Rodríguez R.; Picó Y. \& Mañes J. (2001). Liquid chromatographic-mass spectrometric determination of post-harvest fungicides in citrus fruits. Journal of Chromatography A, 912 (2), 301-310, ISSN 0021-9673.

Fletcher, P.; Andrew K. N.; Calokerinos A. C.; Forbes S. \& Worsfold P. J. (2001). Analytical applications of flow injection with chemiluminescence detection - a review. Luminescence, 16(1), 1-23, ISSN 1522-7235.

García-Reyes, J.F.; Ortega-Barrales, P. \& Molina-Díaz, A.(2004). Development of a Single Fluorescence-Based Optosensor for Rapid Simultaneous Determination of 
Fungicides Benomyl and Thiabendazole in Waters and Commercial Formulations. Journal of Agricultural and Food Chemistry, 52 (8), 2197-2202, ISSN 0021-8561.

Garrido Frenich, A., Picón Zamora, D., Martínez Vidal, J.L., Martínez Galera, M. (2003). Standardization of SPE signals in multicomponent analysis of three benzimidazolic pesticides by spectrofluorimetry. Analytica Chimica Acta, 477 (2), 211-222, ISSN 0003-2670 .

Gros, M.; Petrovic, M. \& Barceló, D. (2006). Multi-residue analytical methods using LCtandem MS for the determination of pharmaceuticals in environmental and wastewater samples: A review. Analytical and Bioanalytical Chemistry, 386 (4), 941952, ISSN 1618-2642.

Guenu S. \& Hennion M.C. (1996). Evaluation of new polymeric sorbents with high specific surface areas using an on-line solid-phase extraction-liquid chromatographic system for the trace-level determination of polar pesticides. Journal of Chromatography A, 737 (1), 15-24, ISSN 0021-9673.

Guo B.; Huang Z.; Wang M.; Wang X.; Zhang Y.; Chen B.; Li Y.; Yan H. \& Yao S. (2010). Simultaneous direct analysis of benzimidazole fungicides and relevant metabolites in agricultural products based on multifunction dispersive solid-phase extraction and liquid chromatography-mass spectrometry. Journal of Chromatography A, 1217 $(29,16), 4796-4807$, ISSN 0021-9673.

Halko, R., Padrón Sanz, C., Sosa Ferrera, Z. \& Santana Rodríguez J.J. (2004). Determination of benzimidazole fungicides by HPLC with fluorescence detection after micellar extraction. Chromatographia, 60 (3-4), 151-156, ISSN 0009-5893

Halko, R., Padrón Sanz, C., Sosa Ferrera, Z. \& Santana Rodríguez J.J. (2006). Determination of benzimidazole fungicides in soil samples using microwave-assisted micellar extraction and liquid chromatography with fluorescence detection. Journal of AOAC International, 89 (5), 1403-1409, ISSN 1060-3271.

Hu, Y.; Yang, X.; Wang C.; Zhao J.; Li W. \& Wang Z. (2008). A sensitive determination method for carbendazim and thiabendazole in apples by solid-phase microextraction-high performance liquid chromatography with fluorescence detection. Food Additives and Contaminants - Part A Chemistry, Analysis, Control, Exposure and Risk Assessment, 25 (3), 314-319, ISSN 1944-0049.

Huebra, M. J. G.; Hernandez P.; Nieto O.; Ballestreros Y. \& Hernandez L. (2000). Determination of carbendazim in soil samples by anodic stripping voltammetry using a carbon fiber ultramicroelectrode. Fresenius' Journal of Analytical Chemistry, 367(5), 474-478, ISSN 0937-0633.

Itak, J. A.; Selisker M. Y.; Jourdan S. W.; Fleeker J. R. \& Herzog D. P.( 1993). Determination of benomyl (as carbendazim) and carbendazim in water, soil, and fruit juice by a magnetic particle-based immunoassay. Journal of Agriculture and Food Chemistry, 41(12), 2329-2332, ISSN 0021-8561.

Jeannot, R.; Sabik, H.; Sauvard, E. \& Genin, E. (2000). Application of liquid chromatography with mass spectrometry combined with photodiode array detection and tandem mass spectrometry for monitoring pesticides in surface waters. Journal of Chromatography A, 879 (1), 51-71, ISSN 0021-9673.

Junker-Buchheit, A. \& Witzenbacher, M. (1996). Pesticide monitoring of drinking water with the help of solid-phase extraction and high-performance liquid chromatography. Journal of Chromatography, A 737 (1), 67-74, ISSN 0021-9673.

Lesueur, C.; Gartner M.; Mentler A. \& Fuerhacker M. (2008). Comparison of four extraction methods for the analysis of 24 pesticides in soil samples with gas chromatography- 
mass spectrometry and liquid chromatography-ion trap-mass spectrometry. Talanta, 75(1), 284-293, ISSN: 0039-9140.

Ling Y.-C. \& Liao J.-H. (1996). Matrix effect on supercritical fluid extraction of organochlorine pesticides from sulfur-containing soils. Journal of Chromatography A, 754 (1-2), 285-294, ISSN 0021-9673.

López-Monzón, A.; Vega-Moreno, D.; Torres Padrón, M.E.; Sosa Ferrera, Z. \& Santana Rodriguez, J.J. (2007). Solid-phase microextraction of benzimidazole fungicides in environmental liquid samples and HPLC-fluorescence determination Comparison with conventional solid-phase microextraction method. Analytical and Bioanalytical Chemistry, 397 1957-1963, ISSN 1618-2642.

Mahugo Santana, C..; Sosa Ferrera, Z. \& Santana Rodríguez, J.J (2004) Use of polyoxyethylene-6-lauryl ether and microwave-assisted extraction for the determination of chlorophenols in marine sediments . Analytica Chimica Acta 524, 133-139, ISSN 0003-2670.

Merino F.; Rubio S. \& Pérez-Bendito D. (2004). Evaluation and optimization of an on-line admicelle-based extraction-liquid chromatography approach for the analysis of ionic organic compounds. Analytical Chemistry, 76 (14), 3878-3886, ISSN 0003-2700.

Melo, L. F. C.; Collins C. H. \& Jardim I. C. S. F. (2005). High-performance liquid chromatographic determination of pesticides in tomatoes using laboratory-made $\mathrm{NH}_{2}$ and $\mathrm{C}_{18}$ solid-phase extraction materials. Journal of Chromatography A, 1073(12), 75-81, ISSN 0021-9673.

Mogadati P.; Louis J.B. \& Rosen J.D. (1999). Multiresidue determination of pesticides in high-organic-content soils by solid-phase extraction and gas chromatography/mass spectrometry. Journal of AOAC Inernational, 82 (3), 705-715, ISSN 1060-3271.

Moral A.; Sicilia M.D.; Rubio S. \& Pérez-Bendito D. (2005). Determination of bisphenols in sewage based on supramolecular solid-phase extraction/liquid chromatography/fluorimetry. Journal of Chromatography A, 1100, 8-14, ISSN 00219673.

Moral A.; Sicilia M.D.; Rubio S. \& Pérez-Bendito D. (2006). Sodium dodecyl sulphate-coated alumina for the extraction/preconcentration of benzimidazolic fungicides from natural waters prior to their quantification by liquid chromatography/fluorimetry. Analytica Chimica Acta, 569(1-2), 132-138, ISSN 0003-2670.

Moral A.; Sicilia M.D. \& Rubio, S. (2009). Supramolecular solvent-based extraction of benzimidazolic fungicides from natural waters prior to their liquid chromatographic/fluorimetric determination. Journal of Chromatography A, 1216 (18), 3740-3745. ISSN 0021-9673.

Plant Protection-Pesticide Residues-Regulation (EC) No. 396/2005. Available at:http:/ / ec.europa.eu/food/plant/protection/pesticides/regulation

Padrón Sanz, C.; Eiguren Fernández, A.; Sosa Ferrera, Z. \& Santana Rodríguez, J.J. (2002). Determination of organochlorinated compounds in marine organisms by microwave-assisted extraction with molecular organized systems and liquid chromatography with fluorescence detection. Journal of AOAC International, 85 (1), 44-49, ISSN 1060-3271.

Padrón Sanz, C.; Halko, R.; Sosa Ferrera, Z. \& Santana Rodríguez J.J. (2005). Combination of microwave assisted micellar extraction and liquid chromatography for the determination of organophosphorous pesticides in soil samples. Journal of Chromatography A, 1078 (1-2), 13-21, ISSN 0021-9673.

Pedersen-Bjergaard S. \& Rasmussen K.E. (2005). Bioanalysis of drugs by liquid-phase microextraction coupled to separation techniques. Journal of Chromatography B: 
Analytical Technologies in the Biomedical and Life Sciences, 817 (1), 3-12, ISSN 15700232.

Petrovic, M.; Farré, M.; de Alda, M.L.; Perez, S.; Postigo, C.; Köck, M.; Radjenovic, J.; (...), Barcelo, D. (2010) Recent trends in the liquid chromatography-mass spectrometry analysis of organic contaminants in environmental samples Journal of Chromatography A, 1217 (25), 4004-4017, ISSN 0021-9673.

Picón D.; Martínez M.; Garrido A. \& Martínez J.L. (2000). Trace determination of carbendazim, fuberidazole and thiabendazole in water by application of multivariate calibration to cross-sections of three-dimensional excitation-emission matrix fluorescence. Analyst, 125 (6), 1167-1174, ISSN 0003-2654.

Pichon V. \& Haupt K. (2006). Affinity separations on molecularly imprinted polymers with special emphasis on solid-phase extraction. Journal of Liquid Chromatography and Related Technologies, 29 (7-8), 989-1023 ISSN 1082-6076.

Prousalis, K. P., Polygenis, D. A; Syrokou, A.; Lamari, F. N. \& Tsegenidis. T. (2004). Determination of carbendazim, thiabendazole, and o-phenylphenol residues in lemons by HPLC following sample clean-up by ion-pairing. Analytical Bioanalytical Chemistry, 379(3), 458-463 ISSN 1618-2642.

Psillakis, E. \& Kalogerakis, N. (2002). Developments in single-drop microextraction . TrACTrends in Analytical Chemistry, 21, 53-63, ISSN 0165-9936.

Psillakis, E. \& Kalogerakis, N. (2003). Developments in liquid-phase microextraction. TrAC Trends in Analytical Chemistry 22 (9), 565-574, ISSN 0165-9936.

Radisic, M..; Gruiic, S.; Vasiljevic, T. \& Lausevic M. (2009). Determination of selected pesticides in fruit juices by matrix solid-phase dispersion and liquid chromatography-tandem mass spectrometry. Food Chemistry, 113(2), 712-719 ISSN 0308-8146.

Radjenović, J.; Petrović, M.; Barceló, D. \& Petrović, M. (2007). Advanced mass spectrometric methods applied to the study of fate and removal of pharmaceuticals in wastewater treatment. TrAC - Trends in Analytical Chemistry 26 (11), 1132-1144, ISSN 0165-9936.

Ramil Criado, M..; Rodríguez Pereiro, I. \& Celo Torrijos, R. (2003). Optimization of a microwave-assisted extraction method for the analysis of polychlorinated biphenyls in ash samples. Journal of Chromatography A 985 (1-2), 137-145, ISSN 00219673.

Rasmussen K.E.; Pedersen-Bjergaard S. (2004). Developments in hollow fibre-based, liquidphase microextraction. TrAC- Trends in Analytical Chemistry, 23 (1), 1-10, ISSN 01659936.

Reddersen, K. \& Heberer, T. (2003). Multi-compound methods for the detection of pharmaceutical residues in various waters applying solid phase extraction (SPE) and gas chromatography with mass spectrometric (GC-MS) detection. Journal of Separation Science, 26 (15-16), 1443-1450, ISSN 1615-9306.

Rezaee, M.; Assadi, Y.; Hosseini, M.R.M. ; Aghaee, E. ; Ahmadi, F. \& Berijani, S. (2006). Determination of organic compounds in water using dispersive liquid-liquid microextraction. Journal of Chromatography A, 1116 (1-2), 1-9, ISSN 0021-9673.

Salinas, A.; Fernández-Sánchez, J.F.; Segura, A., Fernández-Gutiérrez, A. (2005). A simple and rapid phosphorimetric method for the determination of the fungicide fuberidazole in water samples. International Journal of Environmental Analytical Chemistry, 85(7), 443-449, ISSN 0306-7319.

Sánchez-Brunete, C.; Pérez, R.A.; Miguel, E. \& Tadeo, J.L. (1998). Multiresidue herbicide analysis in soil samples by means of extraction in small columns and gas 
chromatography with nitrogen-phosphorus and mass spectrometric detection. Journal of Chromatography A, 823 (1-2), 17-24, ISSN 0021-9673.

Sánchez-Brunete, C.; Miguel, E. \& Tadeo, J.L.(2002). Multiresidue analysis of fungicides in soil by sonication-assisted extraction in small columns and gas chromatography. Journal of Chromatography A, 976 (1-2), 319-327, ISSN 0021-9673.

Sandahl M.; Mathiasson, L. \& Jönsson, J.A. (2000). Determination of thiophanate-methyl and its metabolites at trace level in spiked natural water using the supported liquid membrane extraction and the microporous membrane liquid-liquid extraction techniques combined on-line with high-performance liquid chromatography. Journal of Chromatography A, 893 (1), 123-131, ISSN 0021-9673.

Singh, S. B.; Foster, G. D. \& Khan, S. U. (2007). Determination of thiophanate methyl and carbendazim residues in vegetable samples using microwave-assisted extraction. Journal of Chromatography A, 1148(2), 152-157, ISSN 0021-9673.

Shimamura, Y.; Tomiyama, N.; Murakoshi, M.; Kobayashi, H. \& Matano, O. (1998). Multi Residue Method of Pesticides in Water Using Automated Solid Phase Extraction and Liquid Chromatography-Atmospheric Pressure Chemical Ionization Mass Spectrometry. Journal of Pesticide Sciences, 23 (3), 241-249, ISSN 1348-589X

Shu, Y.Y.; Tey, S.Y. \& Wu, D.K.S. (2003). Analysis of polycyclic aromatic hydrocarbons in airborne particles using open-vessel focused microwave-assisted extraction. Analytica Chimica Acta, 495 (1-2), 99-108, ISSN 0003-2670.

Snyder, J.L.; Grob, R.L.; McNally, M.E \& Oostdyk, T.S. (1993). Effect of instrumental parameters and soil matrix on the recovery of organochlorine and organophosphate pesticides from soils using supercritical fluid extraction. Journal of Chromatographic Science, 31, 183-191, ISSN 0021-9665.

Thomas, O.; Pouet, M.-F. \& Quevauviller, Ph. (1999). Special issue methodologies for wastewater quality monitoring. Talanta 50 (4), 693-694, ISSN 0039-9140.

Turiel, E., Tadeo, J.L., Cormack, P.A,G. \& Martin-Esteban, A. (2005). HPLC imprintedstationary phase prepared by precipitation polymerisation for the determination of thiabendazole in fruit. Analyst 130 (12), 1601-1607, ISSN 0003-2654

Van der Velde, E.G.; De Haan, W. \& Liem, K.D. (1992). Supercritical fluid extraction of polychlorinated biphenyls and pesticides from soil. Comparison with other extraction methods. Journal of Chromatography, 626 (1), 135-143, ISSN 0021-9673.

Waseem, A.; Yaqoob, M. \& Nabi, A. (2007). Flow-Injection Determination of carbaryl and carbofuran based on $\mathrm{KMnO}_{4}-\mathrm{Na}_{2} \mathrm{SO}_{3}$ Chemiluminescence Detection. Luminescence, 22(4), 349-354, ISSN 1522-7235.

Waseem, A.; Yaqoob, M.; Nabi, A. \& Siddiqui, M. A. (2007). Determination of carbaryl by flow injection with luminol chemiluminescence inhibition detection. International Journal of Environmental Analytical Chemistry, 87(12), 825-832, ISSN 0306-7319.

Wu, Q.; Li, Y.; Wang, C.; Liu, Z.; Zang, X.; Zhou, X. \& Wang, Z. (2009). Dispersive liquidliquid microextraction combined with high performance liquid chromatographyfluorescence detection for the determination of carbendazim and thiabendazole in environmental samples. Analytica Chimica Acta, 638 (2), 139-145, ISSN 0003-2670.

Zamora, D. P.; Vidal J. L. M.; Galera M. M.; Frenich A. G.; Gonzalez J. L. L. \& Arahal. M. R. (2003). Correction of predicted concentration in the use of solvent-based calibration lines for determining carbendazim, fuberidazole and thiabendazole in water after a SPE step. Talanta, 60(2-3), 335-344, ISSN 0039-9140.

Zamora, O.; Paniagua, E. E.; Cacho; C.; Vera-Avila, L. E. \& Perez-Conde, C. (2009). Determination of benzimidazole fungicides in water samples by on-line MISPEHPLC. Analytical and Bioanalytical Chemistry, 393, 1745-1753, ISSN 1618-2642. 


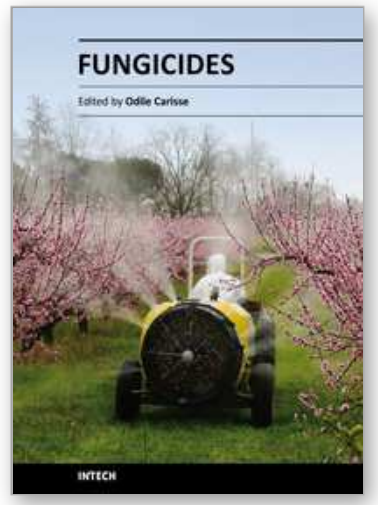

\author{
Fungicides \\ Edited by Odile Carisse
}

ISBN 978-953-307-266-1

Hard cover, 538 pages

Publisher InTech

Published online 14, December, 2010

Published in print edition December, 2010

Plant and plant products are affected by a large number of plant pathogens among which fungal pathogens. These diseases play a major role in the current deficit of food supply worldwide. Various control strategies were developed to reduce the negative effects of diseases on food, fiber, and forest crops products. For the past fifty years fungicides have played a major role in the increased productivity of several crops in most parts of the world. Although fungicide treatments are a key component of disease management, the emergence of resistance, their introduction into the environment and their toxic effect on human, animal, non-target microorganisms and beneficial organisms has become an important factor in limiting the durability of fungicide effectiveness and usefulness. This book contains 25 chapters on various aspects of fungicide science from efficacy to resistance, toxicology and development of new fungicides that provides a comprehensive and authoritative account for the role of fungicides in modern agriculture.

\title{
How to reference
}

In order to correctly reference this scholarly work, feel free to copy and paste the following:

José Juan Santana Rodríguez, Maㅡ Esther Torres Padrón, Jana Aufartová and Zoraida Sosa Ferrera (2010). Benzimidazole Fungicides in Environmental Samples: Extraction and Determination Procedures, Fungicides, Odile Carisse (Ed.), ISBN: 978-953-307-266-1, InTech, Available from:

http://www.intechopen.com/books/fungicides/benzimidazole-fungicides-in-environmental-samples-extractionand-determination-procedures-

\section{INTECH}

open science | open minds

\section{InTech Europe}

University Campus STeP Ri

Slavka Krautzeka 83/A

51000 Rijeka, Croatia

Phone: +385 (51) 770447

Fax: +385 (51) 686166

www.intechopen.com

\section{InTech China}

Unit 405, Office Block, Hotel Equatorial Shanghai

No.65, Yan An Road (West), Shanghai, 200040, China

中国上海市延安西路65号上海国际贵都大饭店办公楼 405 单元

Phone: +86-21-62489820

Fax: $+86-21-62489821$ 
(C) 2010 The Author(s). Licensee IntechOpen. This chapter is distributed under the terms of the Creative Commons Attribution-NonCommercialShareAlike-3.0 License, which permits use, distribution and reproduction for non-commercial purposes, provided the original is properly cited and derivative works building on this content are distributed under the same license. 